\title{
Impact of COVID-19 on child malnutrition, obesity in women and household food insecurity in underserved urban settlements in Sri Lanka: a prospective follow-up study
}

\author{
Renuka Jayatissa $^{1, *}$ (1), Himali P Herath ${ }^{1}$ (1), Amila G Perera ${ }^{1}$ (D), Thulasika T Dayaratne ${ }^{1}$, \\ Nawmali D De Alwis ${ }^{1}$ (D) and Hiyare Palliyage Laksiri K Nanayakkara ${ }^{2}$ \\ 'Department of Nutrition, Medical Research Institute, Sir Danister De Silva Mawatha, Colombo 08, Sri Lanka: \\ ${ }^{2}$ Independent Consultant
}

Submitted 22 December 2020: Final revision received 1 April 2021: Accepted 20 April 2021: First published online 27 April 2021

\begin{abstract}
Objectives: To determine changes and factors associated with child malnutrition, obesity in women and household food insecurity before and after the first wave of COVID-19 pandemic.

Design: A prospective follow-up study.

Setting: In 2019, the baseline Urban Health and Nutrition Study 2019 (UHNS-2019) was conducted in 603 households, which were selected randomly from 30 clusters to represent underserved urban settlements in Colombo. In the present study, $35 \%$ of households from the UHNS-2019 cohort were randomly selected for repeat interviews, 1 year after the baseline study and 6 months after COVID-19 pandemic in Sri Lanka. Height/length and weight of children and women were re-measured, household food insecurity was reassessed, and associated factors were gathered through interviewer-administered questionnaires. Differences in measurements at baseline and follow-up studies were compared.

Participants: A total of 207 households, comprising 127 women and 109 children were included.

Results: The current prevalence of children with wasting and overweight was higher in the follow-up study than at baseline UHNS-2019 (18.3\% v. 13.7\%; $P=0.26$ and $8.3 \% v .3 .7 \% ; P=0.12$, respectively). There was a decrease in prevalence of child stunting $(14.7 \% v .11 .9 \% ; P=0.37)$. A change was not observed in overall obesity in women, which was about $30 \cdot 7 \%$. Repeated lockdown was associated with a significant reduction in food security from $57 \%$ in UHNS-2019 to $30 \%$ in the current study $(P<0 \cdot 001)$.

Conclusions: There was an increase in wasting and overweight among children while women had a persistent high prevalence of obesity. This population needs suitable interventions to improve nutrition status of children and women to minimise susceptibility to COVID-19.
\end{abstract}

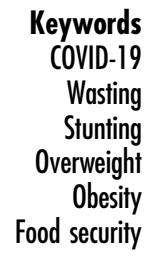

The COVID-19 pandemic threatens the nutrition and food security of millions of people, many of whom are already suffering $^{(1)}$. This pandemic has progressively aggravated issues of global hunger and malnutrition. Pre-existing social, economic and political inequalities have been exposed and exacerbated by the COVID-19 pandemic ${ }^{(2)}$. Furthermore, several COVID-19 response measures such as contact tracing, self-isolation, social distancing and lockdown of communities have led to unhealthy diets and physical inactivity ${ }^{(1)}$. There is a significant concern at a global level as to whether the COVID-19 responses have led to a negative impact on nutritional status of children and women and whether it will worsen with time ${ }^{(1)}$. Additionally, it suggests that economic deterioration, food insecurity and interruption of routine nutrition programmes could increase the prevalence of wasting by $10-50 \%$ with an increase in child mortality ${ }^{(1)}$.

The first COVID-19 case among Sri Lankans was reported on 11 March $2020^{(3)}$. To prevent the spread of COVID-19 infection, the Sri Lankan government imposed 
a 52-d continuous lockdown period up to 11 May 2020 in the Western province, with varying lengths of lockdown periods imposed on other provinces ${ }^{(4,5)}$. The new regulations caused major disruptions of lives and income of the people living in under-served settlements (USS) who were mainly daily wage earners. People in USS were confined to the limited living spaces in their houses with no access to physical activity. Implementation of lockdown regulations were monitored by the police. The government implemented cash transfer and food distribution programmes targeting households below the poverty line. The first wave of the COVID-19 pandemic was successfully controlled. People engaged in most of their routine activities while adhering to health and safety precautions from July to September 2020, before the second wave started in October.

Before the onset of the COVID-19 pandemic, the national prevalence of child wasting, obesity in women and household food insecurity in Sri Lanka was 15\%, $30 \%$ and $15 \%$, respectively ${ }^{(6,7)}$. People in underserved urban settlements were already struggling with food insecurity due to pre-existing crises. They were more nutritionally vulnerable than the rest of the country with a higher prevalence of child malnutrition and obesity in women $^{(8)}$. The vast majority live in very small houses with limited sanitary facilities and depend on daily wages obtained through elementary occupations.

In September 2019, a representative sample of 603 households in underserved urban settlements in the Colombo district was assessed to determine the nutrition and health status of children, women and status of household food security ${ }^{(8)}$. It was observed that the prevalence of child wasting, stunting and overweight was comparable to national rates. However, the prevalence of food insecurity and obesity in women was higher than the national averages ${ }^{(8)}$. Restrictions on movement and activity to control the spread of the pandemic have severely affected the livelihood of the underserved urban settlement population. This has resulted in food insecurity and increased vulnerability to malnutrition. Thus, it is imperative to reassess this cohort of households 6 months after the first local case was reported in the country.

The objective of this study was to determine the changes and associated factors of child wasting, stunting and overweight, obesity in women, and household food insecurity before and after the first wave of COVID-19 pandemic in underserved urban settlements in Colombo.

\section{Methods}

We conducted a prospective follow-up study that included the participants of the Urban Health and Nutrition Study 2019 (UHNS-2019) in selected underserved urban settlements in Colombo district ${ }^{(8)}$.

\section{Study setting and UHNS-2019}

Colombo is the commercial capital of Sri Lanka where nearly $11 \%$ of the total population reside. The population density in Colombo is 3417 persons $/ \mathrm{km}^{2}$, which is ten times the national average of 345.5 persons $/ \mathrm{km}^{2(9)}$. Most of the poor urban population in Colombo district live in slum and shanty settlements termed USS. USS comprises areas that have a concentration of residential units built on state or private land and is not owned by the residents. While these residential areas have common features of a very high population density and congested housing (with each block averaging 1.5 perches), it is the unrelieved condition of services and infrastructure available to these residents that give its name ${ }^{(10-12)}$.

UHNS-2019 was based on a cohort of 603 households with 2237 inhabitants randomly selected from 30 clusters of USS areas in Colombo. There were three key target groups within the selected households for UHNS-2019: children aged 0-59 months; adult men aged 18-59 years and adult women aged 18-59 years. Baseline data on household characteristics, sociodemographic and livelihood data, food security, access to health services, dietary intake and nutrition status were collected in UHNS-2019 ${ }^{(8)}$.

\section{Sample size calculation}

Sample size was calculated to detect a $0 \cdot 2$ difference in weight-for-height- $Z$ (WHZ)/height-for-age- $Z$ (HAZ) with a standard deviation of difference of 0.8 in the paired $t$ test. At $80 \%$ power, assuming a non-response rate of $5 \%$, required sample size for the children aged under 5 years was 135 . For the food security assessment of households by comparing paired proportions, with estimates of proportion of food-secure households in UHNS 2019 at $60 \%$ and current study at 45\%, 196 households were needed at $80 \%$ power and $10 \%$ non-response rate. Due to the second wave of COVID-19, we had to end data collection activities limiting ourselves to 103 children and 207 households. However, post hoc power calculation revealed that the current study had an acceptable power $(72 \%$ power for WHZ and $68 \%$ power for the HAZ) in the paired $t$ test and $>90 \%$ power for comparing paired proportions (food security status).

\section{Data collection}

This follow-up data collection was carried out 1 year after initial recruitment of the cohort and 6 months after the first local COVID-19 case was reported in Sri Lanka as shown in Fig. 1.

This follow-up data collection was carried out 1 year after initial recruitment of the cohort and 6 months after the first local COVID-19 case was reported in Sri Lanka.

Due to the COVID-19 pandemic, follow-up data collection was limited to one-third of the households enrolled in 2019. In this follow-up study, households were randomly sampled from the UHNS-2019 database. Data were 


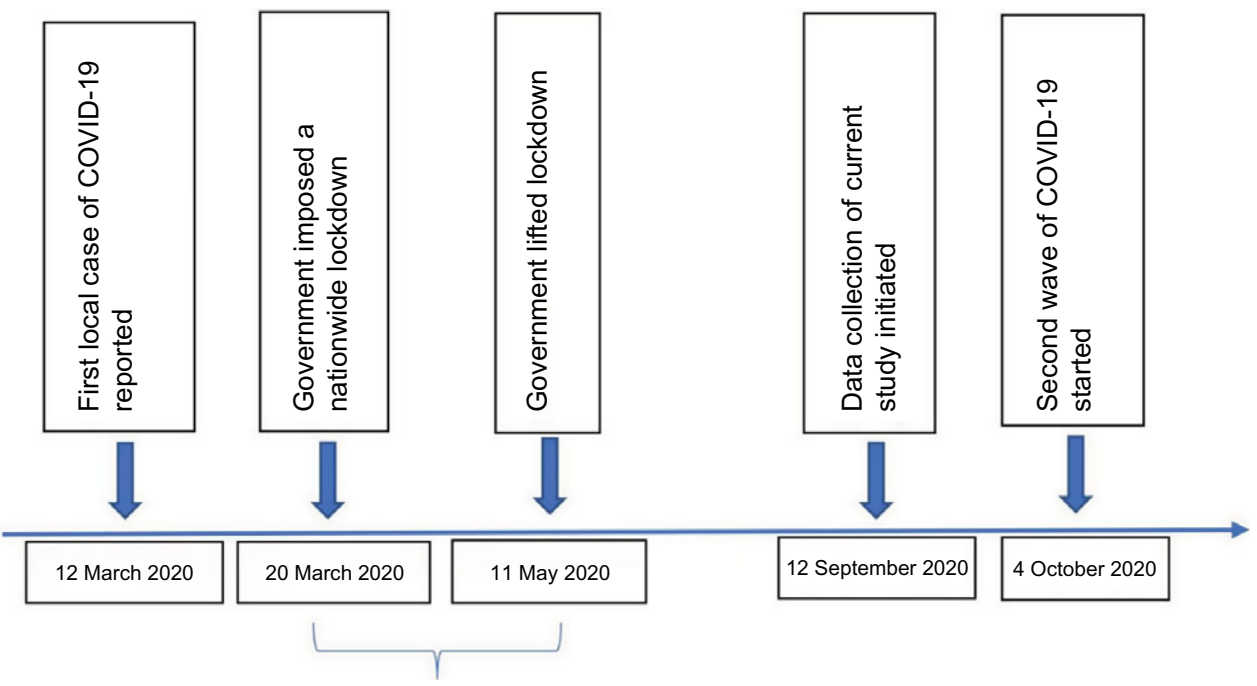

Fig. 1 (colour online) Data collection summary

collected using a brief, pre-tested, structured questionnaire by direct interview. The data collection tool focused on exposure to COVID-19, change in household income and expenditure following the COVID-19 pandemic and household food insecurity in the preceding 6 months. Self-reported COVID-19 status was assessed during the study. During the interview, respondent was asked whether he/she or anyone in the household was confirmed to have COVID-19 based on the polymerase chain reaction (PCR) test. In these selected households, the same adult woman (aged 18-59 years) and child (aged 0-59 months) who participated in the UHNS-2019 were selected to assess nutritional status.

Food insecurity was assessed using the 'Food Insecurity Experience Scale (FIES)' developed by the $\mathrm{FAO}^{(13)}$. Participants were instructed to focus on food-related behaviours and experiences of households during the preceding 6 months (COVID-19 pandemic period) when responding to the eight questions in FIES. This questionnaire was composed of a scale that resulted in the categorisation of these households into food-secure, mild (marginal) food-insecure, moderate food-insecure and severe food-insecure groups.

Anthropometric measurements of adult women and children were taken by trained data collectors who followed WHO standard procedures ${ }^{(14)}$. Weight was measured to the nearest $0.1 \mathrm{~kg}$ using a calibrated seca weighing scale. Height was measured to the nearest $0 \cdot 1$ $\mathrm{cm}$ using a seca stadiometer. Recumbent length (for children $<24$ months of age) was measured using an infant measuring board. The same instruments were calibrated daily and used throughout the study.

Indices of nutritional status of children $<60$ months were derived using the WHO Anthro Survey Analyzer software and children $\geq 60$ months with WHO Anthro Plus software ${ }^{(15)}$. In children aged under 5 years, mild, moderate and severe stunting were defined as HAZ score and WHZ score between -1 SD and $-2 \mathrm{SD} ;-2 \mathrm{SD}$ and -3 $\mathrm{SD}$ and below $-3 \mathrm{SD}$, respectively, from the median World Health Organization Child Growth Standards (WHOCGS). Overweight/obesity in children $<60$ months was defined as $\mathrm{WHZ}>+2$ SD from the median WHOCGS. In children between 5 and 6 years of age, mild, moderate and severe stunting and wasting were defined as HAZ score and BMI-for-age-sex- $Z$ (BAZ) score between $-1 \mathrm{SD}$ and $-2 \mathrm{SD} ;-2 \mathrm{SD}$ and $-3 \mathrm{SD}$ and below $-3 \mathrm{sD}$, respectively, from the median WHOCGS. Overweight/obesity in children between 5 and 6 years of age was defined as BAZ $>+1$ SD from the median WHOCGS. Concurrent wasting and stunting (WaSt) were defined as $\mathrm{WHZ}<-2 \mathrm{SD}$ and $\mathrm{HAZ}<-2 \mathrm{SD}$.

In adult women, BMI was calculated (weight in $\mathrm{kg} /$ height in $\mathrm{m}^{2}$ ). Underweight, normal, overweight, obesity grade 1 , obesity grade 2 and obesity grade 3 (morbid obesity) were defined as $\mathrm{BMI}<18.5,18 \cdot 5-24 \cdot 9,25 \cdot 0$ $29 \cdot 9,30 \cdot 0-34 \cdot 9,35 \cdot 0-39 \cdot 9$ and $\geq 40 \mathrm{~kg} / \mathrm{m}^{2}$, respectively.

Per capita monthly income was calculated by dividing the monthly household income by total number of household members.

The double burden of malnutrition in households was defined as wasting, stunting overweight of children along with overweight, obesity and underweight of women in the same households ${ }^{(16)}$.

\section{Statistical analysis}

Data were analysed using SPSS (version 22.0, IBM, Inc.) software. The Shapiro-Wilk and Kolmogorov-Smirnov tests were used to test the normality of data. Continuous data were presented as mean and standard deviation when normally distributed. Frequencies and percentages were used to summarise categorical variables. Continuous pre- and post-results were compared using paired $t$ test and the categorical, dichotomous pre- and post-variables 
Table 1 Comparison of baseline characteristics of selected households and the UHNS-2019 cohort

\begin{tabular}{lccc}
\hline & $\begin{array}{c}\text { Follow-up study, } \\
\text { September 2020 } \\
(n \text { 207) \% }\end{array}$ & $\begin{array}{c}\text { UHNS-2019, } \\
\text { September 2019 } \\
(n \text { 603) \% }\end{array}$ & $P$ \\
\hline $\begin{array}{c}\text { Number of members in the household } \\
1-3\end{array}$ & 18.8 & & \\
$4-5$ & 52.7 & 47.0 & 0.71 \\
$\geq 6$ & 28.5 & 32.1 & 0.23 \\
Type of the family & & & 0.33 \\
$\quad$ Extended & 37.2 & 39.1 & 0.63 \\
$\quad$ Nuclear & 62.8 & 60.9 & 0.63 \\
Residency status & & & \\
Living since birth & 58.5 & 48.8 & 0.02 \\
Permanent but not & 39.6 & 46.3 & 0.09 \\
$\quad$ living since birth & & & \\
$\quad$ Migrant & 1.9 & 5.0 & 0.06 \\
Ethnicity & & & \\
Sinhalese & 45.5 & 37.8 & 0.11 \\
$\quad$ Tamil & 33.0 & 36.0 & 0.53 \\
Muslim & 21.5 & 25.9 & 0.31 \\
Other & 0.0 & 0.2 & 0.62 \\
\hline
\end{tabular}

UHNS-2019, Urban Health and Nutrition Study 2019.

were compared using the McNemar test. Variables with more than two categories were compared between baseline and follow-up study using McNemar-Bowker test. All tests of significance were two-tailed. A probability level of $P<0.05$ was used to indicate statistical significance in all analyses.

\section{Results}

A total of 207 households from UHNS-2019 cohort were recruited for the follow-up study. Baseline characteristics of selected households were similar to UHNS-2019 sample except for the proportion of people living in USS since birth, which was significantly higher in the current study compared to UHNS-2019 (Table 1). Mean age and standard deviation of the children in the current follow-up study and at baseline in 2019 were $39(\mathrm{SD}=16 \cdot 4)$ months and 26.4 $(\mathrm{SD}=16 \cdot 3)$ months, respectively.

\section{Nutritional status of children and adult women}

Nutritional status of 109 children and 127 women in selected households were assessed in this follow-up study. Mean age and standard deviation of the children in the follow-up study was 39 ( $\mathrm{SD}=16 \cdot 4)$ months.

Mean WHZ and HAZ appear to have increased significantly in this study population (Table 2 ). The proportion of children with moderate to severe wasting was higher, while children with moderate to severe stunting were lower in the follow-up study. However, these differences were not statistically significant $(P>0.05)$. A significant difference was not seen in the distribution of BMI categories in women at baseline and follow-up studies. The prevalence of overweight and obesity among women was more than $60 \%$ in both studies and $2.4 \%$ were morbidly obese. The double burden of malnutrition in households were changed from $13.3 \%$ to $10 \cdot 8 \%$, which was not significant.

When the WHZ and HAZ categories were compared between the follow-up and baseline studies (Fig. 2), there is an increase in the proportion of children with moderate wasting and overweight categories (Fig. 2(a)).

The proportion of children with adequate height has not changed and more children have moved from severe and moderate stunting to the mild stunting category (Fig. 2(b)).

None of the residents of selected households had COVID-19 infection and none were quarantined during the first 6-month period after the first COVID-19 case was reported (Table 3).

Food security and coping strategies of selected households were compared between the two time periods; at baseline UHNS-2019 and the current follow-up study 1 year later (Table 3). Respondents were asked to focus on the preceding 6 months during which the COVID-19 pandemic occurred in Sri Lanka. Nearly half of the food-secure households in the UHNS-2019 were moved into the food insecurity category resulting in a total of two out of three households with food insecurity in the follow-up study. Nevertheless, the severe food-insecure population has reduced compared to last year (11.6\% v. 5.8\%).

The most common coping strategies that were followed for food security needs were borrowing money from friends and use of savings, which was significantly increased in the follow-up study compared to baseline (50.7\%-23.2\%; $P<0.001$ and $48.3 \%-21.3 \% ; P<0.001$, respectively).

About $90 \%$ of households reported a reduction in monthly household income during the preceding 6 months. Main contributory factors for reduced income were loss of employment (64.7\%), deduction of salary by the employer ( $49.2 \%)$ and loss of extra income source (40.1\%).

Over $50 \%$ of households reported increased household expenditure and almost all of these households $(99.1 \%)$ reported an increase in food prices as the main reason.

Highest prevalence of wasting, stunting and concurrent WaSt was observed in children between 24 and 35 months, $<2500 \mathrm{~g}$ of birth weight and from severely food-insecure households (Table 4).

The prevalence of wasting was significantly higher in children who are in the moderately stunted category in the present study, as well as in those who were in moderately wasted and moderately stunted categories 1 year ago. Significant differences were not seen in age, sex, food security, per capita income and wasting at present compared to 1 year ago. 
Table 2 Nutritional status of children and women

\begin{tabular}{|c|c|c|c|c|c|c|c|}
\hline \multirow[b]{2}{*}{ Nutritional status indicator } & \multicolumn{3}{|c|}{ Follow-up study, September 2020} & \multicolumn{3}{|c|}{ UHNS-2019, September 2019} & \multirow[b]{2}{*}{$P$} \\
\hline & $n$ & Mean & SD & $n$ & Mean & SD & \\
\hline \multicolumn{8}{|l|}{ Children ( $n$ 109) } \\
\hline WHZ & 109 & -0.66 & 1.35 & 109 & -0.90 & 1.09 & $0.02^{*}$ \\
\hline \multirow[t]{2}{*}{ HAZ } & 109 & -0.62 & 1.25 & 109 & $-0 \cdot 78$ & 1.24 & $0.009^{*}$ \\
\hline & $n$ & $\%$ & $95 \% \mathrm{Cl}$ & $n$ & $\%$ & $95 \% \mathrm{Cl}$ & \\
\hline Moderate to severe wasting & 20 & $18 \cdot 3$ & $11 \cdot 9,25 \cdot 7$ & 15 & $13 \cdot 7$ & $7 \cdot 3,20 \cdot 2$ & $0.26 \dagger$ \\
\hline Moderate to severe stunting & 13 & 11.9 & $6 \cdot 4,18 \cdot 3$ & 16 & $14 \cdot 7$ & $7 \cdot 4,21 \cdot 1$ & $0.37 \dagger$ \\
\hline Overweight or obese & 9 & 8.3 & $4 \cdot 4,15 \cdot 0$ & 4 & 3.7 & $1 \cdot 4,9 \cdot 1$ & $0.12 \dagger$ \\
\hline Concurrent wasting and stunting & 6 & $5 \cdot 5$ & $2 \cdot 1,11 \cdot 6$ & 6 & 5.5 & $2 \cdot 1,11 \cdot 6$ & $1+$ \\
\hline \multicolumn{8}{|l|}{ Women BMI categories ( $n$ 127) } \\
\hline Underweight & 4 & $3 \cdot 1$ & $1 \cdot 2,7 \cdot 9$ & 5 & $3 \cdot 9$ & $1 \cdot 7,8 \cdot 9$ & $0.4 \ddagger$ \\
\hline Normal & 33 & $26 \cdot 0$ & $19 \cdot 1,34 \cdot 2$ & 34 & $26 \cdot 8$ & $19 \cdot 8,35 \cdot 1$ & \\
\hline Overweight & 51 & 40.2 & $32 \cdot 0,48 \cdot 9$ & 51 & $40 \cdot 2$ & $32 \cdot 0,48 \cdot 9$ & \\
\hline Obesity grade 1 & 24 & $18 \cdot 9$ & $13 \cdot 0,26 \cdot 6$ & 22 & $17 \cdot 3$ & $11 \cdot 7,24 \cdot 8$ & \\
\hline Obesity grade 2 & 12 & 9.4 & $5 \cdot 5,15 \cdot 8$ & 12 & 9.4 & $5 \cdot 5,15 \cdot 8$ & \\
\hline Obesity grade 3 & 3 & $2 \cdot 4$ & $0.8,6.7$ & 3 & $2 \cdot 4$ & $0.8,6.7$ & \\
\hline \multicolumn{8}{|l|}{ DBM in households ( $n$ 109) } \\
\hline DBM & 9 & $10 \cdot 8$ & $4 \cdot 8,18 \cdot 1$ & 11 & $13 \cdot 3$ & $6 \cdot 0,20 \cdot 5$ & $0.3 \dagger$ \\
\hline
\end{tabular}

WHZ, weight-for-height-Z; HAZ, height-for-age-Z; UHNS-2019, Urban Health and Nutrition Study 2019; DBM, double burden of malnutrition.

${ }^{*}$ Paired $t$ test.

†McNemar test.

¥McNemar-Bowker test.

The prevalence of stunting was significantly higher in severely wasted children at present compared to 1 year ago. Age, sex, per capita income, food security at present and 1 year ago were not significantly associated with the current stunting of children.

The prevalence of concurrent WaSt is $5.5 \%$ and it is significantly higher in severely wasted and severely stunted children 1 year ago.

\section{Discussion}

This study investigated the impact of COVID-19 pandemic on wasting, stunting, overweight/obesity and concurrent WaSt in children, obesity in women and food insecurity and double burden of malnutrition of households in underserved urban settlement areas in Colombo. Child wasting is an acute transient condition amenable to treatment with appropriate nutrition and medical interventions. Child stunting is chronic in nature and needs to be prevented ${ }^{(17)}$. The prevalence of concurrent WaSt among children under 5 years of age is an important indicator in child survival ${ }^{(18)}$. All three indicators are important in an emergency situation. Studies on this topic related to COVID-19 pandemic are limited, but a few available studies in other countries depict weight gain or no shift in weight ${ }^{(19)}$. Child wasting, stunting and concurrent WaSt provide wide range of information related to disruption of livelihood in this population due to COVID-19 pandemic. This study is a good example to show how marginalised populations will get affected further. As children are most vulnerable among low-income groups, focusing on child nutrition is needed in this type of population to prevent child malnutrition becoming a public health problem. We must consider these vulnerable groups while adopting universal COVID-19 prevention strategies overall.

In the current study, mean WHZ and HAZ of children have significantly improved over 1 year. However, the prevalence of wasting has increased from $13.8 \%$ to $18.3 \%(P=0.26)$. Current wasting prevalence is above both the national average of $15.3 \%$ and WHO critical level threshold of $15.0 \%{ }^{(20)}$. Although the risk of COVID-19 complications may be lower in children, the potential impact of reduced immunity associated with wasting should not be underestimated in this population ${ }^{(21)}$. Furthermore, it poses a grave concern due to the protracted course of the COVIDpandemic.

A positive change that was observed in this population was the reduction of child stunting, which indicates that shortage of food has not still affected the linear growth of children. However, monitoring of stunted children is important to prevent the long-term consequences during the COVID-19 pandemic due to its uncertain duration. Global experts predict an increased risk in all forms of malnutrition due to economic and food crises during periods of lockdown ${ }^{(22)}$.

It was alarming to observe the increasing number of overweight children in this population. Consuming cheaper products in greater quantities, increased 
(a) WHZ categories at follow-up study 2020 and baseline UHNS-2019

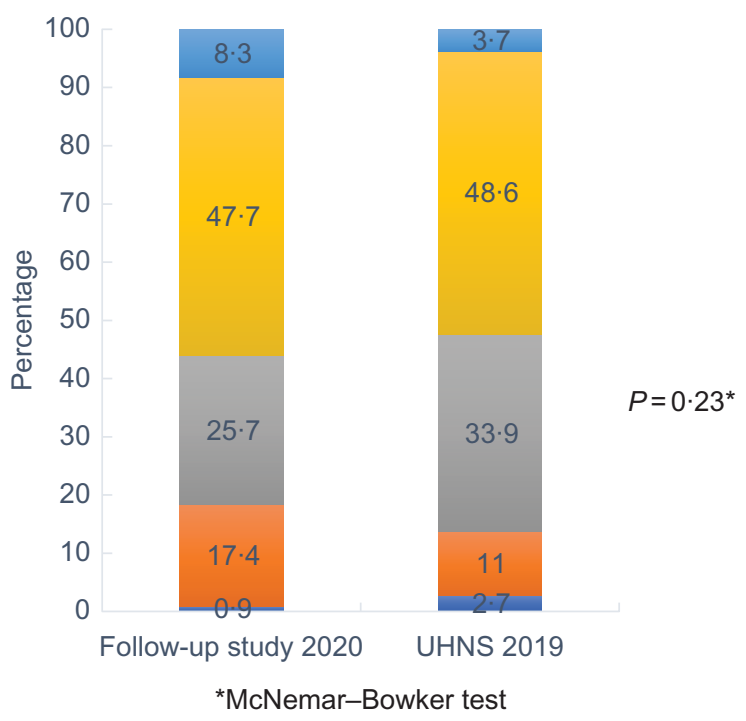

(b) HAZ categories at follow-up study 2020 and baseline UHNS-2019

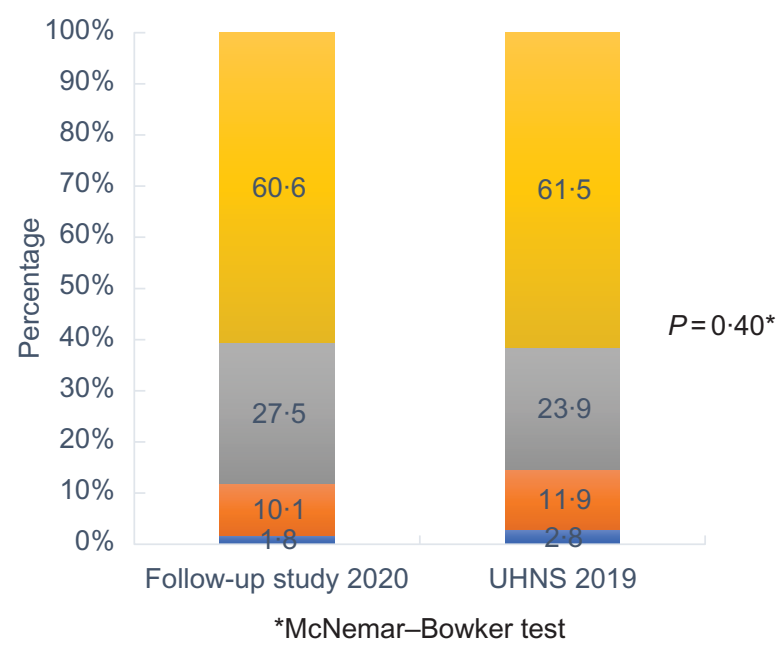

Fig. 2 (colour online) WHZ and HAZ categories at follow-up study in 2020 September and baseline UHNS-2019. WHZ, weight-for-height-Z; HAZ, height-for-age-Z; UHNS-2019, Urban Health and Nutrition Study 2019

consumption of unhealthy food due to limited choices and increased sedentary behaviour during lockdown periods due to limited space in their home settings are possible contributory factors. When the playgrounds in the neighbourhood were closed off and they were mandated to stay at home continuously for $52 \mathrm{~d}$ by the lockdown, children were more susceptible for weight gain. The closure of preschools which extended even beyond the lockdown period resulted in the absence of organised physical activity sessions for the young children. Furthermore, increased screen time that is also associated with increase in snacking, especially most available convenient food like sugary biscuits may be another contributory factor for the increase in overweight. Consistent findings have been reported in other countries ${ }^{(23,24)}$.

However, a change in obesity was not observed in women during the past year. This may become aggravated due to restrictions imposed on movement and changes in dietary habits due to economic hardships until solution is available for the COVID-19 pandemic. Considering the high level of obesity and $2.4 \%$ morbid obesity in women, continuous monitoring is needed to prevent complications and increased susceptibility to this infection.

A worsening trend in food insecurity was observed in this population. The most probable reason could be frequent disruptions to their livelihoods due to repeated mandatory lockdowns to prevent disease transmission. These results further indicate that the pandemic has affected all income groups, which impacts the purchasing power of a household, worsening food insecurity. FIES may be a useful tool to measure trends and severity of food insecurity during COVID-19 pandemic, as it is based on participant responses to eight questions regarding constraints on their ability to obtain adequate food ${ }^{(13)}$.

To cope with a reduced income, participants have increased rate of borrowing, which was also observed in the UHNS-2019 study. Similar observations were made in other populations whose earning opportunities were abandoned $^{(25-28)}$. Other coping strategies that were observed in the current study include taking loans and selling assets, which will exacerbate poverty and inadvertently affect child stunting in the future. All these indicate a weakened resilience in USS in Colombo due to the COVID-19 pandemic.

Our study further shows that stunted children are more likely to become severely wasted and severely wasted children are more likely to develop concurrent WaSt. Early detection and appropriate treatment of concurrent WaSt should be prioritised and steps should be taken via the health care system to minimise its impact on child survival.

Similar to other studies, our study suggests that severe wasting in children can lead to stunting ${ }^{(18)}$. Furthermore, two-thirds of severely wasted children in the past year remain wasted indicating the importance of revisiting existing intervention programmes. However, it should be interpreted with caution due to small sample size and studies with larger sample sizes are needed to confirm it. Concurrent WaSt deserves more attention during the COVID-19 pandemic because of its impact on child survival $^{(18)}$. This study indicates that presence of severe stunting and severe wasting in the past are good indicators to identify high-risk children for concurrent WaSt if these children have not attended routine growth monitoring clinics due to lockdown. The lack of a significant association between household food insecurity and child malnutrition in our study implies that merely improving 
Table 3 Exposure to COVID-19 infection, food security status, changes in household income and expenditure during the COVID-19 pandemic (n 207)

\begin{tabular}{|c|c|c|c|c|c|}
\hline \multirow[b]{2}{*}{ Characteristic } & \multicolumn{2}{|c|}{$\begin{array}{l}\text { Follow-up study, } \\
\text { September } 2020\end{array}$} & \multicolumn{2}{|c|}{$\begin{array}{c}\text { UHNS-2019, } \\
\text { September } 2019\end{array}$} & \multirow[b]{2}{*}{$P$} \\
\hline & $n$ & $\%$ & $n$ & $\%$ & \\
\hline \multicolumn{6}{|l|}{ Exposure to COVID-19 infection } \\
\hline Infected & 0 & 0.0 & - & - & \\
\hline Quarantined & 0 & 0.0 & - & - & \\
\hline \multicolumn{6}{|l|}{ Food security status } \\
\hline Severe food insecurity & 12 & $5 \cdot 8$ & 24 & 11.6 & $<0.001^{*}$ \\
\hline Moderate food insecurity & 50 & $24 \cdot 2$ & 30 & 14.5 & \\
\hline Mild food insecurity & 82 & 39.6 & 35 & $16 \cdot 9$ & \\
\hline Food secure & 63 & 30.4 & 117 & $57 \cdot 0$ & \\
\hline \multicolumn{6}{|l|}{ Main coping mechanisms } \\
\hline Sold household or productive assets & 46 & $22 \cdot 2$ & 35 & $16 \cdot 9$ & $0.16 \dagger$ \\
\hline Reduced non-food cost (education, health, etc) & 55 & $26 \cdot 6$ & 24 & 11.6 & $<0.001 \dagger$ \\
\hline Spent savings & 100 & $48 \cdot 3$ & 44 & $21 \cdot 3$ & $<0.001 \dagger$ \\
\hline Borrowed money from bank & 42 & $20 \cdot 3$ & 29 & $14 \cdot 0$ & $0.1 \dagger$ \\
\hline Borrowed food/money from friends/relatives & 105 & $50 \cdot 7$ & 48 & $23 \cdot 2$ & $<0.001 \dagger$ \\
\hline Looked for additional income sources & 35 & 16.9 & 23 & $11 \cdot 1$ & $0.1 \dagger$ \\
\hline \multicolumn{6}{|l|}{ Per capita monthly income (USD) } \\
\hline$<27$ & 50 & $24 \cdot 2$ & 23 & $11 \cdot 1$ & $<0.001^{*}$ \\
\hline $27-41$ & 53 & $25 \cdot 6$ & 43 & $20 \cdot 8$ & \\
\hline $40 \cdot 1,59$ & 53 & $26 \cdot 1$ & 67 & 32.9 & \\
\hline$>59 \cdot 1$ & 51 & $24 \cdot 2$ & 73 & $35 \cdot 3$ & \\
\hline \multicolumn{6}{|l|}{ Change in household income during last 6 months } \\
\hline Increased & 2 & 1.0 & - & - & \\
\hline Decreased & $18 \overline{7}$ & $90 \cdot 3$ & - & - & \\
\hline No change & 18 & $8 \cdot 7$ & - & - & \\
\hline \multicolumn{6}{|c|}{ Reasons to decrease household income during last 6 months ( $n 187$ ) } \\
\hline Loss of employment & 121 & $64 \cdot 7$ & - & - & \\
\hline No extra income & 75 & $40 \cdot 1$ & - & - & \\
\hline Deduct the salary by employee & 92 & $49 \cdot 2$ & - & - & \\
\hline \multicolumn{6}{|c|}{ Change in household expenditure during last 6 months } \\
\hline Increased & 110 & $53 \cdot 1$ & - & - & \\
\hline Decreased & 33 & $15 \cdot 9$ & - & - & \\
\hline No change & 64 & 30.9 & - & - & \\
\hline \multicolumn{6}{|c|}{ Reasons to increase household expenditure during last 6 months ( $n 110)$} \\
\hline High food price & 109 & $99 \cdot 1$ & - & - & \\
\hline Paid school fees & 32 & $29 \cdot 1$ & - & - & \\
\hline Paid loans/vehicle lease & 30 & $27 \cdot 3$ & - & - & \\
\hline Medicine cost & 27 & 24.5 & - & - & \\
\hline
\end{tabular}

UHNS-2019, Urban Health and Nutrition Study 2019

*McNemar-Bowker test.

†McNemar test.

household food security may not be sufficient to improve the nutritional status of children in this population. Therefore prevention, early detection and appropriate treatments are needed for children with wasting, stunting and concurrent WaSt to minimise their susceptibility to the COVID-19 infection.

This is the first follow-up study in Sri Lanka to assess the impact of COVID-19 on nutrition status and food security in USS. The main strength of this study revolves around repeated measurements of same households and individuals by the same research team. However, the small sample size is a limitation as we had to minimal interactions with households due to social restrictions imposed during the pandemic. Access and coverage of nutrition services were not assessed in this study. Since this was a rapid assessment with short contact time with the study participants, we did not collect information on any food assistance received and access and coverage of nutrition services which could have better explained the findings.

\section{Conclusions}

In underserved urban settlements of Sri Lanka, there is an increase in the prevalence of child wasting and overweight after the first wave of COVID-19 pandemic. Overall child wasting is alarmingly high and we recommend providing supplementary food for children less than 5 years of age while paying attention to overweight children. There is an urgent need to focus on morbidly obese women to minimise their susceptibility to COVID-19 and to control unhealthy weight gain of women to prevent further increase in obesity. This population needs to be monitored for food security on a long-term basis as repeated lockdowns may worsen the outcome. 
Table 4 Prevalence of wasting (moderate to severe), stunting (moderate to severe) and concurrent wasting and stunting (WaSt) by background characteristics in the follow-up study 2020

\begin{tabular}{|c|c|c|c|c|}
\hline \multirow[b]{2}{*}{ Variables } & Wasting & Stunting & WaSt & \multirow[b]{2}{*}{$n$} \\
\hline & \multicolumn{3}{|c|}{$\%$} & \\
\hline \multicolumn{5}{|l|}{ Age of the child in months } \\
\hline $12-23$ & 13.6 & 4.5 & 4.5 & 22 \\
\hline $24-35$ & $23 \cdot 3$ & 23.3 & $13 \cdot 3$ & 30 \\
\hline $36-47$ & $20 \cdot 8$ & $4 \cdot 2$ & $4 \cdot 2$ & 24 \\
\hline $48-59$ & 12.5 & $12 \cdot 5$ & 0.0 & 16 \\
\hline$\geq 60$ & $18 \cdot 8$ & $12 \cdot 5$ & 5.9 & 17 \\
\hline \multicolumn{5}{|l|}{ Sex of the child } \\
\hline Male & $19 \cdot 0$ & $12 \cdot 7$ & $6 \cdot 2$ & 63 \\
\hline Female & 17.4 & $10 \cdot 9$ & 6.5 & 46 \\
\hline \multicolumn{5}{|l|}{ Birth weight of the child $(g)$} \\
\hline$<2500$ & $35 \cdot 3$ & $17 \cdot 6$ & $11 \cdot 1$ & 17 \\
\hline $2500-3000$ & $14 \cdot 3$ & 11.9 & 4.8 & 41 \\
\hline$>3000$ & 14.9 & $10 \cdot 6$ & $6 \cdot 4$ & 51 \\
\hline \multicolumn{5}{|l|}{ Current wasting of children } \\
\hline Severe $(<-3 \mathrm{SD})$ & - & ** $100 \cdot 0$ & - & 1 \\
\hline Moderate ( -3 SD to $-2 \mathrm{SD})$ & - & $26 \cdot 3$ & - & 19 \\
\hline Mild $(-2$ SD to $-1 S D)$ & - & $3 \cdot 6$ & - & 28 \\
\hline Adequate $(>-1 \mathrm{SD})$ & - & $9 \cdot 8$ & - & 61 \\
\hline \multicolumn{5}{|l|}{ Wasting of children 1 year back } \\
\hline Severe $(<-3 \mathrm{SD})$ & ${ }^{\star \star *} 66 \cdot 7$ & $33 \cdot 3$ & **33.3 & 3 \\
\hline Moderate $(-3 \mathrm{SD}$ to $-2 \mathrm{SD})$ & $75 \cdot 0$ & $25 \cdot 0$ & $25 \cdot 0$ & 12 \\
\hline Mild $(-2$ SD to $-1 S D)$ & $16 \cdot 2$ & $10 \cdot 8$ & $2 \cdot 7$ & 37 \\
\hline Adequate $(>-1 \mathrm{SD})$ & $5 \cdot 3$ & $8 \cdot 8$ & 3.4 & 58 \\
\hline \multicolumn{5}{|l|}{ Current stunting of children } \\
\hline Severe $(<-3 \mathrm{SD})$ & ${ }^{* *} 0.0$ & - & - & 2 \\
\hline Moderate $(-3 \mathrm{SD}$ to $-2 \mathrm{SD})$ & 54.5 & - & - & 11 \\
\hline Mild $(-2$ SD to $-1 S D)$ & $23 \cdot 3$ & - & - & 30 \\
\hline Adequate $(\geq-1 \mathrm{SD})$ & $10 \cdot 6$ & - & - & 66 \\
\hline \multicolumn{5}{|l|}{ Stunting of children 1 year back } \\
\hline Severe $(<-3 \mathrm{SD})$ & **33.3 & $* \star * 100 \cdot 0$ & $\star * \star * 33.3$ & 3 \\
\hline Moderate ( -3 SD to $-2 \mathrm{SD})$ & $46 \cdot 2$ & $69 \cdot 2$ & $30 \cdot 8$ & 13 \\
\hline Mild $(-2 \mathrm{SD}$ to $-1 \mathrm{SD})$ & $26 \cdot 9$ & 3.8 & 3.8 & 26 \\
\hline Adequate $(\geq-1 \mathrm{SD})$ & $9 \cdot 0$ & 0.0 & 1.5 & 68 \\
\hline \multicolumn{5}{|l|}{ Current food security status } \\
\hline Food secure & $21 \cdot 2$ & $11 \cdot 1$ & $8 \cdot 8$ & 63 \\
\hline Mild food insecurity & $14 \cdot 3$ & $6 \cdot 2$ & $4 \cdot 8$ & 82 \\
\hline Moderate food insecurity & $15 \cdot 4$ & $22 \cdot 2$ & 3.8 & 50 \\
\hline Severe food insecurity & 37.5 & $8 \cdot 3$ & 12.5 & 12 \\
\hline \multicolumn{5}{|l|}{ Food security 1 year back } \\
\hline Food secure & $20 \cdot 6$ & $12 \cdot 1$ & $7 \cdot 8$ & 117 \\
\hline Mild food insecurity & $6 \cdot 2$ & 9.5 & 0.0 & 35 \\
\hline Moderate food insecurity & $16 \cdot 7$ & 11.5 & $5 \cdot 6$ & 30 \\
\hline Severe food insecurity & $25 \cdot 0$ & $25 \cdot 0$ & 8.3 & 24 \\
\hline \multicolumn{5}{|c|}{ Current household per capita income (USD) } \\
\hline$<27$ & $22 \cdot 6$ & $16 \cdot 1$ & $9 \cdot 7$ & 50 \\
\hline $27-41$ & $13 \cdot 8$ & $6 \cdot 9$ & 0.0 & 53 \\
\hline $40 \cdot 1-59$ & $22 \cdot 6$ & $12 \cdot 9$ & 6.5 & 53 \\
\hline$>59 \cdot 1$ & $11 \cdot 1$ & $11 \cdot 1$ & 10.5 & 51 \\
\hline \multicolumn{5}{|c|}{ Household per capita income 1 year back (USD) } \\
\hline$<27$ & $20 \cdot 0$ & $20 \cdot 0$ & $10 \cdot 0$ & 23 \\
\hline $27-41$ & 21.4 & $14 \cdot 3$ & $7 \cdot 1$ & 43 \\
\hline $40 \cdot 1-59$ & 21.4 & 11.9 & $9 \cdot 3$ & 67 \\
\hline$>59 \cdot 1$ & 10.3 & $6 \cdot 9$ & 0.0 & 73 \\
\hline \multicolumn{5}{|c|}{ Pattern of household income during last 6 months } \\
\hline Increased & 0.0 & 0.0 & 0.0 & 2 \\
\hline Decreased & $19 \cdot 4$ & $13 \cdot 3$ & $7 \cdot 1$ & 187 \\
\hline No change & $10 \cdot 0$ & 0.0 & 0.0 & 18 \\
\hline Pattern of household expendi & nonths & & & \\
\hline Increased & $20 \cdot 3$ & $15 \cdot 6$ & $9 \cdot 2$ & 110 \\
\hline Decreased & $18 \cdot 8$ & 12.5 & $6 \cdot 2$ & 33 \\
\hline No change & 13.8 & 3.4 & 0.0 & 64 \\
\hline Total & $18 \cdot 3$ & 11.9 & 5.5 & 109 \\
\hline
\end{tabular}

${ }^{\star *} P<0.01$

${ }^{* * *} P<0.001$ 


\section{Acknowledgements}

Acknowledgements: The authors thank the staff of the Department of Nutrition, Medical Research Institute, Ministry of Health, Sri Lanka, for data collection. Financial support: Ministry of Health, Colombo. Conflict of interest: There are no conflicts of interest. Authorship: R.J., H.H., A.G.P.D., N.D.D.A. and L.N. conceptualised, designed, data analysed and wrote the paper. All authors read the manuscript, made a substantial contribution to the revision and approved the final manuscript. Ethics of buman subject participation: This study was conducted according to the guidelines laid down in the Declaration of Helsinki and all procedures involving research study participants were approved by the ethics committee of Medical Research Institute (MRI). Written informed consent was obtained from all adult participants and parent/guardian of children.

\section{References}

1. Akseer N, Kandru G, Keats EC et al. (2020) COVID-19 pandemic and mitigation strategies: implications for maternal and child health and nutrition. Am J Clin Nutr 112, 251-256.

2. Sachs JD, Abdool KS, Aknin L et al. (2020) COVID-19 commission statement on the occasion of the 75th session of the UN General Assembly. Lancet 396, 1102-1124.

3. Ministry of Health \& Indigenous Medical Services (2020) Coronavirus disease 2019 (COVID-19) - Situation ReportEpidemiology Unit. http://www.epid.gov.lk/web/images/ pdf/corona_virus_report/sitrep-sl-en-12-03_10.pdf (accessed December 2020)

4. Government of Sri Lanka (2020) National Operation Centre for Prevention of COVID-19 Outbreak. Official Website for Sri Lanka's Response to Covid-19 (Coronavirus). https:// covid19.gov.lk/ (accessed December 2020).

5. Sri Lanka (2020) Resumption of civilian life and office work to begin from May 11. http://www.colombopage.com/archive_ 20A/May01_1588349980CH.php (accessed December 2020).

6. Department of Census and Statistics, Ministry of National Policies \& Economic Affairs (2017) Sri Lanka Demographic and Health Survey 2016. Health Sector Development Project Ministry of Health, Nutrition and Indigenous Medicine. http://www.statistics.gov.lk (accessed December 2020).

7. Jayatissa R, Fernando D, Herath H et al. (2017) National Nutrition Survey of Lactating Women in Sri Lanka. Colombo, Sri Lanka: Medical Research Institute; available at http://maternal nutritionsouthasia.com/wp-content/uploads/national-nutritionsurvey-of-lactating-women.pdf (accessed December 2020).

8. Jayatissa R, Herath H \& Fernando D (2020) Nutrition Status, Food Consumption Pattern, Livelihood and Food Security of Housebolds in Urban Underserved Settlements in Colombo District. Colombo, Sri Lanka: Medical Research Institute.

9. World Bank (2018) Population density (people per sq. km of land area) - Sri Lanka. https://data.worldbank.org/indicator/ EN.POP.DNST?locations=LK (accessed November 2020).

10. Rathnayake I (2014) Urban Poverty in Sri Lanka-2013. Centre for Poverty Analysis (CEPA). http://www.cepa.lk/content_ images/publications/documents/PB21.pdf (accessed July 2020).
11. Gunetilleke N, Cader AA \& Fernando M (2004) Understanding the Dimensions and Dynamics of Poverty in Underserved Settlements in Colombo. Sri Lanka: Centre for Poverty Analysis.

12. Ministry of Megapolis and Western Development (2018) Resettlement policy framework for Colombo urban regeneration project. https://www.uda.gov.lk/RPF_updated.pdf (accessed November 2020).

13. Food and Agriculture Organization of the United Nations (2020) Food Insecurity Experience Scale. http://www.fao. org/in-action/voices-of-the-hungry/fies/en/ (accessed November 2020).

14. World Health Organization (1995) WHO Technical Report series 854. Physical status: the use and interpretation of anthropometry. WHO; available at https://apps.who.int/ iris/handle/10665/37003 (accessed March 2021).

15. World Health Organization (2009) WHO AnthroPlus for Personal Computers Manual Software for assessing growth of the world's children. WHO; available at https://www. who.int/growthref/tools/who_anthroplus_manual.pdf (accessed March 2021).

16. World Health Organisation (2016) The double burden of malnutrition. Policy brief. WHO-https://NMH-NHD-17.3eng.pdf (accessed March 2021).

17. United Nations Children's Fund (2020) The Global Nutrition Cluster. Risk of COVID-19 complications in children affected by wasting. UNICEF; available at https://aa9276f9-f487-45a2a3e7-8f4a61a0745d.usrfiles.com/ugd/aa9276_a57d468ed 8c5489fb574872a81bf2d36.pdf (accessed December 2020).

18. Briend A, Garenne M, Myatt M et al. (2019) Concurrent wasting and stunting among under-five children in Niakhar, Senegal. Matern Child Nutr 15, e12736.

19. Popkin BM, Du S, Green WD et al. (2020) Individuals with obesity and COVID-19: A global perspective on the epidemiology and biological relationships. Obes Rev 21, e13128.

20. World Health Organization (2010) Nutrition Landscape Information System (NLIS) Country Profile indicators: Interpretation Guide. WHO; available at https://apps.who. int/iris/handle/10665/44397 (accessed March 2021).

21. Pradhan PMS, Dhital R \& Subhani H (2016) Nutrition interventions for children aged less than 5 years following natural disasters: a systematic review. BMJ Open 6, e011238.

22. Headey D, Heidkamp R, Osendarp S et al. (2020) Impacts of COVID-19 on childhood malnutrition and nutrition-related mortality. Lancet 396, 519-520.

23. Ammar A, Brach M, Trabelsi K et al. (2020) Effects of COVID19 home confinement on eating behaviour and physical activity: results of the ECLB-COVID19 international online survey. Nutrients 12, 1583.

24. Werneck AO, Silva DR, Malta DC et al. (2021) Associations of sedentary behaviours and incidence of unhealthy diet during the COVID-19 quarantine in Brazil. Public Health Nutr 24(3), 422-426. doi: 10.1017/S1368980020004188.

25. Gaitán-Rossi P, Vilar-Compte M, Teruel G et al. (2021) Food insecurity measurement and prevalence estimates during the COVID-19 pandemic in a repeated cross-sectional survey in Mexico. Public Health Nutr 24(3), 412-421. doi: 10.1017/ S1368980020004000.

26. Niles MT, Bertmann F, Belarmino EH et al. (2020) The early food insecurity impacts of COVID-19. Nutrients 12, 2096.

27. World Vision Bangladesh (2020) COVID 19 - Rapid Impact Assessment Report. https://www.wvi.org/sites/default/files/ 2020 (accessed December 2020).

28. Manfrinato CV, Marino A, Ferreira Condé V et al. (2020) High prevalence of food insecurity, the adverse impact of COVID19 in Brazilian favela. https://doi.org/10.1101/2020.07.31. 20166157 (accessed December 2020). 